\title{
La transformación social requiere de reformas más profundas
}

\section{La criminalidad, principal preocupación del país}

Según el último sondeo de opinión pública del IUDOP, la delincuencia, el crimen y la violencia constituyen el principal problema del país para las dos terceras partes de la población. La situación de inseguridad es un problema antiguo; los sondeos del IUDOP de los años 2006 y 2010 ya le daban el primer lugar. Lo novedoso es que, a finales de 2011, el $66 \%$ de la población está de acuerdo en que la violencia, el crimen y la delincuencia son la mayor preocupación de los salvadoreños. Este porcentaje es el más alto en la última década, siendo únicamente superado por la problemática económica en los años 2004 y 2008.

El estudio realizado por el IUDOP, a finales del mes de noviembre 2011, ofrece importantes luces para entender el porqué de esta tan alta preocupación de los ciudadanos por la situación delincuencial que vive el país. En primer lugar, ello se debe al incremento real de la actividad delictiva. Durante 2011, $22.8 \%$ de los encuestados fue víctima de un delito, en lugar del $19.8 \%$ del año pasado. Si a ello le añadimos el incremento en el número de homicidios, que desgraciadamente superan a los cometidos en 2010, no es difícil concluir que realmente la inseguridad de la población ha aumentado a lo largo de este año.

Junto al hecho del incremento en el accionar delictivo, hay otros elementos que afectan a los salvadoreños y aumentan su preocupación. La ciudadanía ha perdido confianza en las instituciones que tienen por misión enfrentar el crimen y opina que están siendo muy poco eficaces en el combate del delito. Entre ellas, se lleva el primer lugar la Fiscalía General de la República, que, siendo la institución rectora en el combate contra el crimen, solo goza de la confianza del $9.7 \%$ de la población. Además, dos terceras partes de los salvadoreños consideran que la Fiscalía es muy ineficiente en la tarea de combatir el delito. Si a ello se le suma que el $43.7 \%$ de los consultados opina que el narcotráfico ha aumentado en el país a lo largo del último año, es comprensible que la preocupación por la inseguridad ciudadana alcance tan altos niveles entre la población.

Para la opinión pública salvadoreña, las medidas que el Gobierno ha tomado para contrarrestar el crimen han sido insuficientes y no han tenido los resultados esperados. En este marco, llama la atención que una tercera parte de la población confíe en que la situación de inseguridad mejorará el próximo año. Por una parte, la situación es ya tan dura y difícil que solo queda 
esperar una mejora; de lo contrario, la vida en el país se volvería insoportable. Pero también abona a esta confianza el nombramiento y las promesas concretas de combate a la delincuencia del nuevo ministro de Seguridad Pública y Justicia, general Munguía Payés. A pesar de que muchos opinamos y tenemos razones de peso para afirmar que no es sano que un militar esté al frente de la seguridad pública, la desesperante situación que viven los salvadoreños lleva a que un $67 \%$ esté de acuerdo con el nombramiento.

Sin embargo, como es obvio, no se obtendrán mejores resultados con el simple cambio del titular del Ministerio. Se requieren muchas otras cosas para enfrentar la criminalidad. Deben revisarse y corregirse los planes de seguridad de todos los entes del Estado; debe mejo-

Si la economía no mejora, si no se crean más puestos de trabajo, si los jóvenes siguen sin encontrar mejores oportunidades, difícilmente harán mella en la criminalidad las medidas que pueda tomar el Gobierno. rarse la eficiencia de la PNC; la Fiscalía General debe superar su negligencia e incapacidad, y mostrar una voluntad decidida para el combate contra el crimen; $y$ en el sistema judicial, deben dejar de pelearse unos contra otros para ofrecer a la población una pronta y debida justicia, con jueces que actúen bajo los principios de la ley, libres de influencias e inmunes a la compra de voluntades por parte de los criminales. Solo así la situación mejorará en el futuro.

Si bien la grave situación delincuencial ha relegado el problema económico a un segundo lugar, ello no significa que la economía esté mejor hoy que el año pasado. La visión de la población al respecto es bastante pesimista; la mayoría piensa que la situación económica sigue igual o ha empeorado. Así, un $81.5 \%$ considera que el costo de la vida se ha incrementado, y las expectativas de mejora para el próximo año son bajas. Y este es otro factor importante que tener en cuenta en la lucha contra el crimen. Si la economía no mejora, si no se crean más puestos de trabajo, si los jóvenes siguen sin encontrar mejores oportunidades, difícilmente harán mella en la criminalidad las medidas que pueda tomar el Gobierno.

\section{Se requiere de un nuevo modelo de desarrollo}

Por otro lado, la economía nacional no logra despegar. Las incertidumbres en las economías europea y estadounidense, que no logran recuperarse de una manera clara de la crisis, provocada por la crisis financiera del año 2008, siguen afectando negativamente a nuestra economía, aunque la misma lleva años con un nivel de crecimiento muy inferior al de los países vecinos y más cerca del estancamiento que de un bajo crecimiento. Según el Informe de Desarrollo Humano del 2010, el modelo de desarrollo seguido en los últimos sesenta años ha mostrado ser incapaz de generar riqueza para la mayoría de la población; en cambio, sí ha sido eficiente para la concentración y apropiación de la misma en muy pocas manos. Se requiere de un cambio de modelo que pueda ser capaz de producir un verdadero crecimiento en la economía y, a su vez, que sea capaz de generar inclusión. El mismo informe del PNUD propone como alternativa un modelo de desarrollo centrado en la gente, que es la mayor riqueza del país, y el camino que 
han seguido países nórdicos y otros como Singapur, que en una generación han logrado altos índices de crecimiento económico y un gran desarrollo de la mayoría de la población.

La inversión en la gente supone un Estado con capacidad de recursos para realizar esta inversión y que, en primer lugar, siente las bases de una educación de calidad y universal. El sistema educativo nacional está en crisis. Este año el resultado promedio a nivel nacional, de la PAES, ha sido más bajo que el año pasado, lo que para muchos es una evidencia más de la crisis de la educación pública nacional. Es difícil mejorar la educación sin un mayor presupuesto para el MINED y para la educación superior. Pero los ingresos fiscales no dan para aumentar el presupuesto, el cual, en los últimos años, ha ido cargando con un déficit creciente y ha incremento el nivel de la deuda pública por encima de lo que el FMI considera prudente.

\section{La impostergable reforma fiscal}

La inversión social del Gobierno del presidente Funes requiere de fondos adicionales que ya no puede obtener por la vía del endeudamiento. A su vez, la ANEP no quiere ni hablar de nuevos o mayores impuestos, sino que acusa al Gobierno del FMLN de despilfarrador y de que nunca tendrá suficiente por mucho que crezcan los ingresos fiscales del Estado. Durante todo este año, el Gobierno y la empresa privada han estado hablando de la necesidad de un pacto fiscal, pero han sido incapaces de sentarse en una mesa para llegar a un acuerdo o siquiera para ver el camino que podría llevar hacia un futuro pacto fiscal. La presión del FMI para mantener el "acuerdo stand by" para El Salvador ha sido mayor que el deseo del presidente Funes de llegar a un acuerdo previo con la empresa privada

La enorme desigualdad social del país requiere un sistema de redistribución de la riqueza que le permita al Estado responder a las necesidades de la población más desfavorecida. sobre la reforma fiscal, $y$ finalmente, en diciembre, el ejecutivo presentó su proyecto de reforma del impuesto sobre la renta, a la Asamblea Legislativa, para su aprobación antes del cierre del año.

La reforma que el Gobierno ha presentado y que, después de pequeñas modificaciones, obtuvo para su aprobación los votos de todos los partidos a excepción de Arena tiene cuatro ejes fundamentales: (1) incremento del impuesto a las utilidades netas de las empresas y un nuevo impuesto sobre los dividendos que se distribuyan entre los accionistas; (2) mayor progresión en el impuesto sobre la renta de las personas naturales, exonerando del impuesto a las rentas más bajas e incrementando la tasa hasta un máximo del $30 \%$ para las más altas; (3) nuevo sistema de retención de impuestos que le permitirá al Estado ingresar fondos a lo largo de todo el año y no tener que recurrir a préstamos para hacer frente a los gastos corrientes; y (4) simplificación del sistema de la declaración de renta.

La reforma fiscal, que se esperaba que el presidente Funes propusiera en los primeros meses de su gobierno era impostergable. Había sido recomendada por los técnicos de organismos internacionales como el FMI, el Banco 
Mundial y el Banco Interamericano de Desarrollo, que en privado habían declarado, hace un par de años, que lo peor que podía hacer el Gobierno salvadoreño era no hacer nada al respecto. Su urgencia responde a varios factores. Uno de los de más peso: la enorme desigualdad social del país requiere de un sistema de redistribución de la riqueza que le permita al Estado responder a las necesidades de la población más desfavorecida. Los ingresos que el Estado obtiene con el sistema fiscal actual son insuficientes para cumplir con sus obligaciones, incluso para cubrir sus gastos corrientes. Ello ha llevado a un incremento de la deuda pública que, de continuar creciendo, dejará las finanzas públicas gravemente comprometidas a futuro. Por otra parte, El Salvador ha dado su palabra a organismos internacionales, de que alcanzará una carga tributaria del $17 \%$ del PIB para el año 2014 . Y esto no podía lograrse sin una reforma fiscal.

La propuesta que ha planteado el Gobierno del presidente Funes está basada en un principio muy importante para una política fiscal justa. La carga impositiva debe ser progresiva: a mayores ingresos, más alto el impuesto que pagar. Además, es muy acertado que la propuesta contemple eliminar el impuesto sobre la renta para los salarios menores a 469 dólares, pues, dado el alto costo de la vida, ese ingreso apenas alcanza para los gastos de una familia. Ello beneficiará a las familias de menores ingresos, que, por ende, tendrán una mayor capacidad adquisitiva mensualmente; y también supondrá un ahorro en la administración de Hacienda, pues se reducirá la cantidad de procesos de devolución de las retenciones a cuenta del impuesto.

Como era de esperar, las asociaciones empresariales y el partido Arena se han pronunciado totalmente en contra de la reforma, incluso una vez aprobada han amenazado con no cumplir con la ley. Las acusaciones de que es una propuesta populista, que no es el momento oportuno, que va ahuyentar la inversión y debilitará al sector empresarial son parte de la cantaleta acostumbrada siempre que se habla de una mayor carga fiscal. La verdad es que ninguna de estas afirmaciones se sostiene después de un análisis detallado. Es deber de un Gobierno defender los ingresos económicos de los hogares más pobres y velar para mantener su poder adquisitivo, por lo que disminuir el impuesto sobre la renta del sector con ingresos más bajos es conveniente para todos. Si los hogares tienen más dinero disponible, consumirán más y, por tanto, las empresas venderán más. Costa Rica y Nicaragua, los países de la región que tienen mayor carga fiscal, están recibiendo más inversión extranjera. Y ello es prueba de que la carga fiscal no ahuyenta las inversiones. Jamás hemos oído decir a los empresarios de El Salvador que es un buen momento para incrementar los impuestos. En contraste, en este tiempo de crisis, algunos grandes empresarios europeos han solicitado que se incrementen los impuestos para exigir mayor responsabilidad social a los que más tienen.

En la afirmación en que sí coincidimos con los empresarios y Arena es que el Gobierno debe ser más austero y eficiente. Duele que, en un país pobre como el nuestro, se gaste en grandes camionetas para los funcionarios, en recepciones casi diarias en hoteles, en propaganda para mostrar lo que 
hacen los funcionarios públicos, cuando ese dinero hace falta para mejorar la salud y la educación. Pero esta austeridad que le exigimos al Gobierno también se la pedimos a los empresarios y a los políticos, pues son ellos los primeros en despilfarrar en artículos lujosos, en fiestas costosísimas y en un nivel de vida que excede las posibilidades de nuestro país. Por eso les duele la reforma fiscal, porque de algún modo esta les obligará a ser un poco más austeros y a ser más eficientes en sus empresas. La reforma fiscal es un paso hacia una mayor solidaridad de los que más tienen con el resto del país. Y si va acompañada de un uso eficiente y austero de los recursos públicos, es el camino adecuado para hacer posible el desarrollo en El Salvador.

\section{Una reforma fiscal condicionada por la contienda electoral}

La reforma fiscal -que, como hemos señalado, favorece a los grupos sociales con salarios medios y a aquellos sectores de profesionales asalariados- está condicionada por la próxima contienda electoral. Ninguno de los partidos quiere perjudicar a este importante grupo social que constituye la mayoría que realmente decide quién gana o pierde las elecciones. Por ello, la reforma aprobada apenas afecta los impuestos que tendrán que pagar las clases medias y sí supone un fuerte impacto en los grupos de rentas más altas, que según los números del Ministerio de Hacienda no son más de dos decenas de miles de contribuyentes. Por esta razón, dicha reforma es incompleta y es muy probable que, según el resultado electoral, se tenga una próxima reforma para el siguiente año que sí afectaría a todos los sectores sociales, dado que hay buenas razones para creer que en esa ocasión se incremente la tasa general del IVA.

\section{Elecciones con una ley electoral reformada}

Si la reforma fiscal ha estado influenciada por las futuras elecciones legislativas y municipales, estas se realizarán con una ley electoral que también ha sido modificada. Esta reforma no ha brotado de la iniciativa de los propios partidos ni de sus legisladores, sino de la decisión de la Sala de lo Constitucional de hacer respetar la Constitución de la República, la cual exige el voto directo de los diputados y -según la interpretación de cuatro de sus magistrados- no prohíbe la participación en las elecciones legislativas de candidatos independientes.

La falta de voluntad de los partidos políticos para acatar la Constitución y su negativa a renunciar al control partidario de la elección de los diputados ha significado varias reformas hasta encontrar una fórmula que satisfaga tanto a la Sala de lo Constitucional como a los partidos políticos. Ello ha retrasado la aprobación de la ley electoral y este retraso tendrá un impacto muy negativo en el proceso electoral. Según la encuesta del IUDOP, la gente mayoritariamente desconoce la nueva forma de votación en las próximas elecciones. Aunque el $63 \%$ de la población salvadoreña afirma saber que se votará por bandera y fotografía, el $83 \%$ dice que ha recibido muy poca o ninguna información sobre el procedimiento. En palabras claras y concisas: la gente no sabe cómo se votará. La Asamblea Legislativa acaba de 
establecer que estarán permitidas hasta ocho formas de ejercer el sufragio, lo que permite hacerse una idea sobre las dudas y problemas que tendrá la población a la hora de marcar la papeleta. Si no se hace algo serio, integral $e$ intensivo para informar y orientar sobre todos los detalles de la votación, se corre el grave riesgo de que, en marzo de 2012, se celebren las elecciones más cuestionadas y controversiales de la historia reciente de nuestro país.

Ojalá y queden atrás los tiempos en que el presidente de la República se quitaba la camisa de primer mandatario y se ponía la de su partido aduciendo, con cinismo, que lo hacía en horas no laborales. al manoseo que han hecho de ellas los partidos para no perder sus cuotas de poder. En este contexto, es fundamental que la sociedad civil se mantenga vigilante y exija una campaña informativa sobre las modalidades del voto por diputados. Si ello no sucede y persiste la confusión, la responsabilidad será de los partidos políticos, y a ellos habrá que pasarles la factura.

\section{Por primera vez, los funcionarios públicos no harán campaña}

Pero la forma de votar no es lo único nuevo en estas elecciones. En esta contienda electoral hay una novedad por resaltar que es muy positiva y representa un avance en el proceso democrático, aunque a algunas personas o instancias les cueste reconocerlo. Por primera vez en la historia electoral del país, el Gobierno central se ha desmarcado de la participación político-partidaria. Es decir, la lamentable costumbre de poner las estructuras del Estado y hasta la misma persona del presidente en función de la campaña política se ha roto con el Gobierno actual. Ojalá y queden atrás los tiempos en que el presidente de la República se quitaba la camisa de primer mandatario y se ponía la de su partido aduciendo, con cinismo, que lo hacía en horas no laborales. Como dijimos antes, la decisión de no participar y no permitir que los funcionarios participen en actos proselitistas representa un avance significativo que no debe pasar inadvertido. Esto, señores políticos de oficio, es muy bueno para el país y debería seguirse como norma en las futuras administraciones.

\section{Un nuevo escenario electoral}

Estas elecciones también marcan un hito en la historia política del país. Los nombres de dos partidos tradicionales desaparecerán de las papeletas: el Partido de Conciliación Nacional (PCN) y el Partido Demócrata Cristiano (PDC), partidos que han perdido su personería jurídica - de nuevo gracias a la decisión de hacer cumplir la Constitución, que han asumido cuatro magis- 
trados de la Sala de lo Constitucional- por no haber obtenido el porcentaje mínimo de votos que la Constitución establece para todo partido o coalición de partidos que participe en unas elecciones. Aunque los titulares de dichos partidos se resistieron a la desaparición de los mismos hasta que no tuvieron alternativa, ello no significa que no van a participar en estas elecciones. Tanto el PCN como el PDC han cambiado de nombre y de bandera para inscribirse nuevamente como partidos y así poder jugar. Según el sondeo del IUDOP, es muy probable que estos partidos tampoco logren los votos suficientes para sobrevivir después de estas elecciones.

Por el contrario, el nuevo partido Gran Alianza Nacional, escindido de ARENA después de que este partido perdiera las elecciones presidenciales del año 2009, ha logrado atraer a más votantes y ocupar el papel que tenía tradicionalmente el PCN, contando con un $7.2 \%$ de las intenciones de voto. Lo más llamativo es la recuperación que ARENA ha tenido en la intención de voto a lo largo de los dos últimos años. Poco a poco, ha ido recuperando el terreno perdido y se ha puesto prácticamente a la par del FMLN. Un posible empate técnico entre ambos partidos no solo complicará más la dinámica electoral, dado lo complejo del nuevo sistema de conteo de votos, sino que pondrá en cuestión la continuidad del FMLN al frente del ejecutivo en el próximo periodo presidencial.

A dos años y medio del Gobierno de Mauricio Funes, esta contienda electoral municipal y legislativa será más que una simple elección, será también una evaluación ciudadana del primer Gobierno del FLMN. A juzgar por el estudio del IUDOP, la actuación de este no cuenta con el beneplácito mayoritario de la población. Un grupo importante de la población (71.8\%) está pidiendo un cambio de rumbo. Conviene que tanto Mauricio Funes como el FLMN tomen nota de ello y busquen una estrategia para responder con efectividad a las demandas de la ciudadanía y a los graves problemas que atañen al país. De su capacidad de hacerlo en la segunda mitad de su período, dependerá el apoyo futuro de la población y la continuidad del Gobierno del cambio al frente del país. 